\title{
Fiber Bragg grating application to study an unmanned aerial system composite wing
}

\author{
Nicolás Gutiérrez ${ }^{\mathrm{a},{ }^{*}}$, Rosario Fernández ${ }^{\mathrm{a}}$, Pedro Galvín ${ }^{\mathrm{b}}$ and \\ Fernando Lasagni ${ }^{\mathrm{a}}$
}

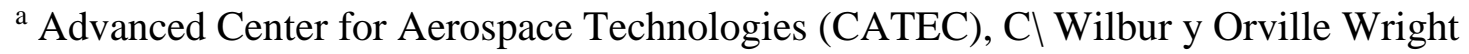 19, 41309 La Rinconada (Sevilla), Spain
E-mail: ngutierrez@catec.aero, rfernandez@ catec.aero, flasagni@ catec.aero

\author{
${ }^{\mathrm{b}}$ Escuela Técnica Superior de Ingeniería, Universidad de Sevilla, Camino de los \\ Descubrimientos s/n, 41092 Sevilla, Spain \\ E-mail: pedrogalvin@us.es
}

\author{
* Corresponding author \\ Preprint submitted to Journal of Intelligent Material Systems and Structures
}

\begin{abstract}
Structural Health Monitoring (SHM) consists of structural integrity assessment by means of data acquisition and analysis from on-board sensors. Fiber Bragg Grating (FBG) based monitoring is increasingly attracting the scientific community working on SHM, due to its multiple advantages such as electromagnetic immunity, negligible weight and size, multiplexing availability, etc. However, the integration of fiber optics within a structure still requires new procedures and signal treatment techniques for increasing technology reliability and exploiting its full potential. In this paper, five embedded FBG sensors are installed in an Unmanned Aerial System (UAS) wing for correlating operational conditions with structural strain in real time. Sensor locations are determined by a finite element model accounting for manufacturing limitations of the fiber line. The developed FBG system and processing techniques are used in static and dynamic tests showing the capacities of this powerful technology. The assessment includes deflection shape estimation, strain cycles counting, audible and visual strain alarms, aileron control based on strain levels and structural resonance response detection.
\end{abstract}

\section{Keywords}

Smart structure; Fibre Bragg Grating; strain monitoring; Unmanned Aerial Vehicles; Unmanned Aerial Systems. 


\section{Introduction}

SHM focuses on the study and development of systems for obtaining information about the structural integrity. This discipline appeared in the late 80 's when engineers began to consider the concept of health monitoring, especially in civil and aerospace fields (Balageas, 2002). The main objectives of SHM are increasing safety and reducing operational costs (Doebling et al., 1996; Farrar and Worden, 2007; Li et al., 2015; Sohn et al., 2004). The adoption of SHM principles and methods allows a series of advantages over traditionally designed and implemented systems. First, the structure is continuously monitored, attempting to detect incipient damage. Any change on load history, geometry or structural characteristics can be noted and taken into account for further actions if needed. Hence, the life of structures can be safely extended thanks to a deep knowledge of their operational response. Furthermore, maintenance philosophy can evolve from time to condition-based approach. This method permits performing inspections when needed instead of using a foreseen calendar, reducing the off-service time. Additionally, structural data can be collected to update numerical models, allowing more accurate predictions for future designed products.

Several researches about SHM have been presented in the last years. Some authors have proposed SHM methodologies based on the response measured by electrical sensors. Among others, Johnson et al. (Johnson et al., 2004) or Solís et al. (Solís et al., 2013, 2018) developed investigations about damage detection using piezoelectric accelerometers. Strain gauges have also been used in SHM applications since they are a precise sensor to measure strains. For example, O'Connor et al. (O’Connor et al., 2010) used strain gauges for fatigue cycles counting. Others authors have developed Lamb waves inspection methods. Senyurek (Senyurek, 2015) and Zhao et al. (Zhao et al., 2007) used these methods to detect, localize and quantify damage. This technology, although very promising, still requires relatively simple geometries and a large number of transductors to be sufficiently accurate.

Fiber Bragg Gratings are strain and temperature sensors implemented in the core of fiber optics. They have recently supposed an important improvement due to their multiple 
advantages and they have pushed SHM investigations (Kang et al., 2005; Kang and Chung, 2009; Luyckx et al., 2013). Several works have been published about this topic. Yuan et al. (Yuan et al., 2008) used FBGs, Lamb waves and strain gauges for detecting damage in a wing box. Aktaş et al. (Aktaş et al., 2009) studied the detection of damage produced by impacts of different energies including results from infrared thermography and a final autopsy. Park et al. (Park et al., 2010) and Choi et al. (Choi et al., 2010) implemented a FBG sensor network for damage monitoring and compared the strain measured by FBGs, piezoelectric active sensors and q-switch pulsed lasers. García et al. (García et al., 2015) presented several practical applications for structures and engines with different alternatives for measuring strains. Li et al. (Li et al., 2013) worked on a deformable aeronautic profile and measured the displacement from the Von-Karman strain-displacement relation. Fernández et al. (Fernández et al., 2016) used FBGs for monitoring aircraft cabin pressurizing tests. FBGs have also been used extensively in wind turbines industry for strain state characterization (Arsenault et al., 2013; H-I Kim et al., 2013).

Lately, another disruptive technology is the Unmanned Aerial Vehicles (UAV) or Systems (UAS), more commonly known as drones. The International Remotely Piloted Aircraft Systems Society has estimated the total quantity of referenced UAS from at approximately 500 in 2005 to 2200 in 2015 (International RPAS Community, 2015). New generation autopilot systems and low-cost consumer electronics have made them reliable and inexpensive enough to be mass-produced. Their uses extend from toy, entertainment and sports to research and defense industries. The new capacities available are causing an impact on the society as it was analyzed by Rao et al. (Rao et al., 2016). UAVs allow aerial filming or inspection from dangerous points of views or risky environments, people or objectives tracking, urgent transportation, mapping, people rescue, etc. Furthermore, they can also be used as development platforms for testing and improving technologies before installing them on manned aircrafts.

In this paper, a wing that is a part of an UAS manufactured in Glass/Carbon Fiber Reinforced Plastics (GFRP/CFRP, respectively) has been monitored with embedded FBG sensors. The objective of this work is to estimate the strain response of the structure in real time. The paper is organized as follows. First, the FBGs and the acquisition system 
are described. Next, the material and geometry of the UAS are presented. A Finite Element Model (FEM) is developed for estimating wing static and dynamic properties. The results from numerical analysis are used to determine the sensor locations accounting for the manufacturing limitations. Static and dynamic tests are carried out for validating the proposed approach to study structural integrity. Finally, some conclusions are drawn.

\section{FBG description and data acquisition}

FBGs have many advantages in relation to other sensors like strain gauges, digital image correlation systems, piezoelectric transducers or other displacement/strain measuring devices. They work based on light instead of electricity. This makes possible their use in explosive or conductive environments with no risks. They are resistant to corrosion, lightnings, electromagnetic interference, etc. Depending on the measurement equipment and application, one fiber can transmit information from many sensors (up to 80 sensors per channel in Micron Optics SM130-700, (Micron Optics, 2015)) and they can be easily multiplexed into different channels, increasing even more the number of measuring points. They are sensitive to strain and temperature depending on the installed configuration. The fiber core and cladding can withstand temperatures higher than $800^{\circ} \mathrm{C}$, although mechanical coatings reduce their temperature tolerance to $80-150^{\circ} \mathrm{C}$ for acrylate and $300-400^{\circ} \mathrm{C}$ for polyimide. They can be integrated into composite materials during fabrication, allowing the monitoring of curing and manufacturing processes since their low size and temperature tolerance.

FBG sensors are manufactured exposing the fiber core to an intense ultraviolet (UV) source, such as an UV laser, using interference or masking (Kreuzer, 2006). Any of these processes produces a pattern of permanent refractive index, so called grating or fixed index modulation. Then, the light suffers an interaction when finding the grating. Some wavelengths suffer strong back-reflection, meanwhile the rest is transmitted. The central wavelength of the reflected signal satisfies the Bragg relation (Equation 1):

$$
\lambda_{\text {Bragg }}=2 n \Lambda
$$


being $n$ the index of refraction and $\Lambda$ the grating period. Changes of temperature or strain on the fiber modify this period and the Bragg wavelength and, therefore, they can be measured.

The signals from the sensors can be read by means of a broad-spectrum light or tunable laser in front of a spectrometer or synchronized photodiode. Tunable lasers and spectrometers are the most common procedure used in industry. Data received from the equipment can be in the form of full spectrum intensity data or wavelengths of identified reflected peaks or sensors. This last option is used in this work.

Strain or temperature are recorded by transformation of the measured wavelength. As a linear approach, for the case of fiber subjected only to small strains, this relation is given by:

$$
\Delta \varepsilon=\left(\Delta \lambda / \lambda_{0}\right) /_{K}
$$

where $\Delta \lambda$ and $\lambda_{0}$ are the increment and initial Bragg wavelength, respectively, and $K$ is the conversion coefficient or gauge factor.

The $K$ factor differs slightly from applications, authors and products. For example, Frövel (Frövel, 2006) used values from 0.788 to 0.825 , and HBM company recommends a value of 0.78 (Kreuzer, 2006). In order to accurately estimate this value, an experimental campaign for CFRP structures was carried out by the authors using strain gauges as reference sensors. This research concluded a best-fit value of $K=0.813$.

This study is developed in a temperature controlled environment, therefore temperature effects on FBGs are not considered. In case of real conditions, the authors have previously used calibrated thermoresistance sensors (i.e. TMP36 (Analog Devices, 2008)) in combination with the FBG sensitivity coefficient of $9.9 \mathrm{pm} /{ }^{\circ} \mathrm{C}$ (Micron Optics, 2008) to subtract the effect of temperature from FBG measures (Gutierrez, 2018).

The equipment used in the present research for acquiring FBG data is an interrogator Micron Optics (MO) SM-130-700. It is equipped with a tunable laser ranging from $1510 \mathrm{~nm}$ to $1590 \mathrm{~nm}$ at a sampling frequency of $1000 \mathrm{~Hz}$ in four channels simultaneously, $2 \mathrm{pm}$ of typical wavelength stability and $1 \mathrm{pm}$ of repeatability. FBG sensors were MO OS1200 with a marked length of approximately $10 \mathrm{~mm}$, with a peak reflectivity superior to $70 \%$, strain sensitivity of $1.2 \mathrm{pm} / \mu \varepsilon$, polyimide coating and a 
theoretical strain limit of $5000 \mu \varepsilon$ (MicronOptics, 2015). Carbon fiber composites have a typical elongation at breakage up to $12000 \mu \varepsilon$. These sensors could not be suitable for registering high loading conditions in the wing. In this study, the wing is subjected to strains below the design limit of the sensors. The MO OS1200 fiber line has $6 \mathrm{~m}$ long with five FBG sensors spaced at $1 \mathrm{~m}$, core-cladding of 9/125 $\mu \mathrm{m}$ and up to $145-165 \mu \mathrm{m}$ with polyimide recoating. Fiber was plugged-in through FC/APC connectors.

\section{The Unmanned Aerial System}

\subsection{Materials and Geometry}

This work studies a wing that was extracted from commercial UAS 'Locomove' developed by the Avionics and Systems division at CATEC technology center (Figure 1(a)). Locomove is the result of a CATEC internal project for developing its own UAS system in collaboration with the Faculty of Engineering of Universidad de Sevilla. Manuel García designed it as his degree final project in aeronautics (Rivero, 2010). The aircraft can be launched into flight by hand and it lands over the belly. It possesses a total weight of $4.2 \mathrm{~kg}$, it is propelled by an electric engine. It is designed for aerial surveillance and for so it can transport equipment up to $0.5-0.6 \mathrm{~kg}$. Its maximum speed is $38.8 \mathrm{knots}$, inducing a maximum load factor of 2.4 over the wing.
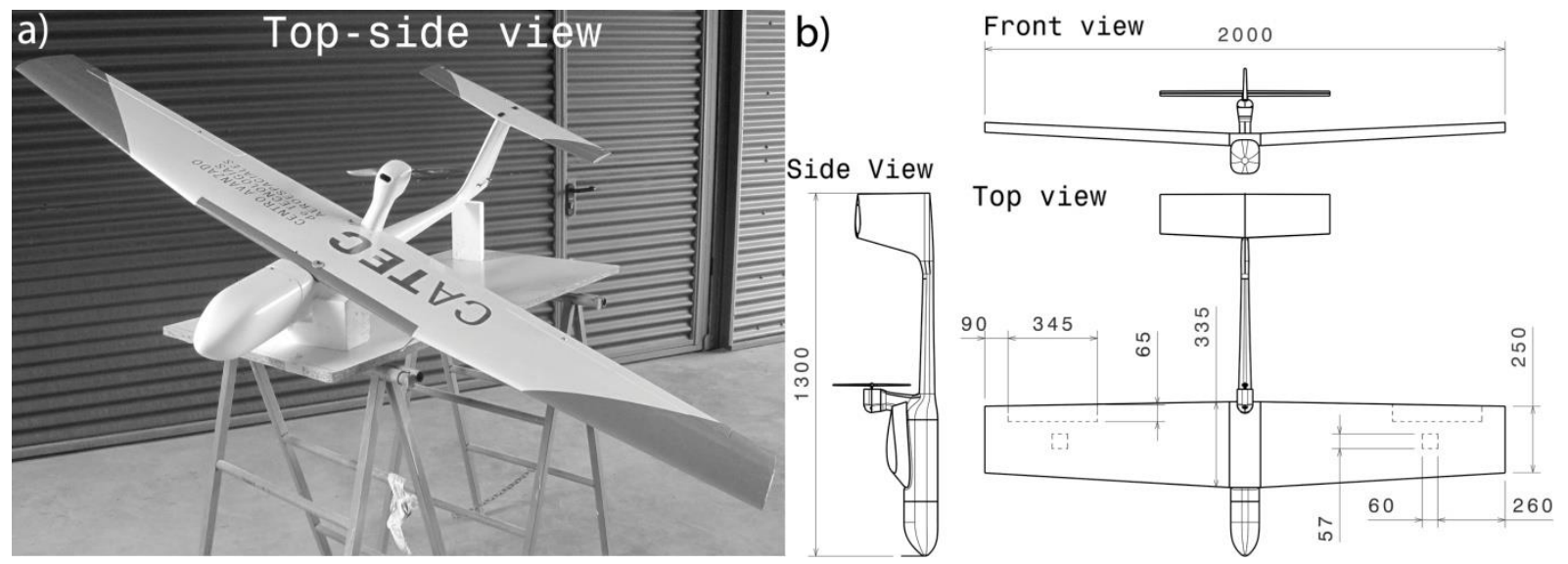

Figure 1. UAS Locomove developed by the Avionics and Systems division at CATEC: a) top-side view and b) front, top and side view drawings. Dimensions in $\mathrm{mm}$. 
Locomove's main geometric characteristics are $1300 \mathrm{~mm}$ length, $2000 \mathrm{~mm}$ span, a mean chord of $285 \mathrm{~mm}$ (with $335 \mathrm{~mm}$ root and $250 \mathrm{~mm}$ tip chord), sweep and dihedral angles of $2.3^{\circ}$ and $2^{\circ}$, respectively, taper ratio 0.75 and airfoil maximum thickness of $45 \mathrm{~mm}$. The wing is equipped with a pitot-tube, servo hatches and ailerons on both sides. The ailerons size is $65 \mathrm{~mm} \times 345 \mathrm{~mm}$, and they are positioned at $90 \mathrm{~mm}$ from the wing tip. Servos are installed centered respect to the chord at $260 \mathrm{~mm}$ from the tip in boxes with size $60 \mathrm{~mm} \times 57 \mathrm{~mm}$ each one. Figure 1(b) shows front, top and side drawings of the UAS.

Figure 2 shows wing materials and manufacturing procedure of the analyzed wing: (I) it was originally based on a foam core (density $10 \mathrm{~kg} / \mathrm{m}^{3}$ ), extracted with a hot wire cutting machine, covered with two layers of twill woven GFRP with density $0.163 \mathrm{~kg} / \mathrm{m}^{2}$; (II) on top of these layers, a $10 \mathrm{~mm}$ width sheet of unidirectional CFRP was set longitudinally to the span along the $25 \%$ chord line, and the root was additionally stiffened with a layer of woven CFRP that extends $20 \mathrm{~mm}$ from the symmetry plane; the original design of the wing as part of the Locomove finishes in this step. (III) Then, FBG sensors were installed on the surface and finally, the wing was covered with two extra CFRP fabrics $\left(0.200 \mathrm{~kg} / \mathrm{m}^{2}\right.$-twill). All the layers were applied by means of wet hand lay-up. After the manufacturing, the element was cut at approximately $1050 \mathrm{~mm}$ length. The step III of manufacturing is developed to increase the stiffness of the wing and to allow the embedding of the sensors.

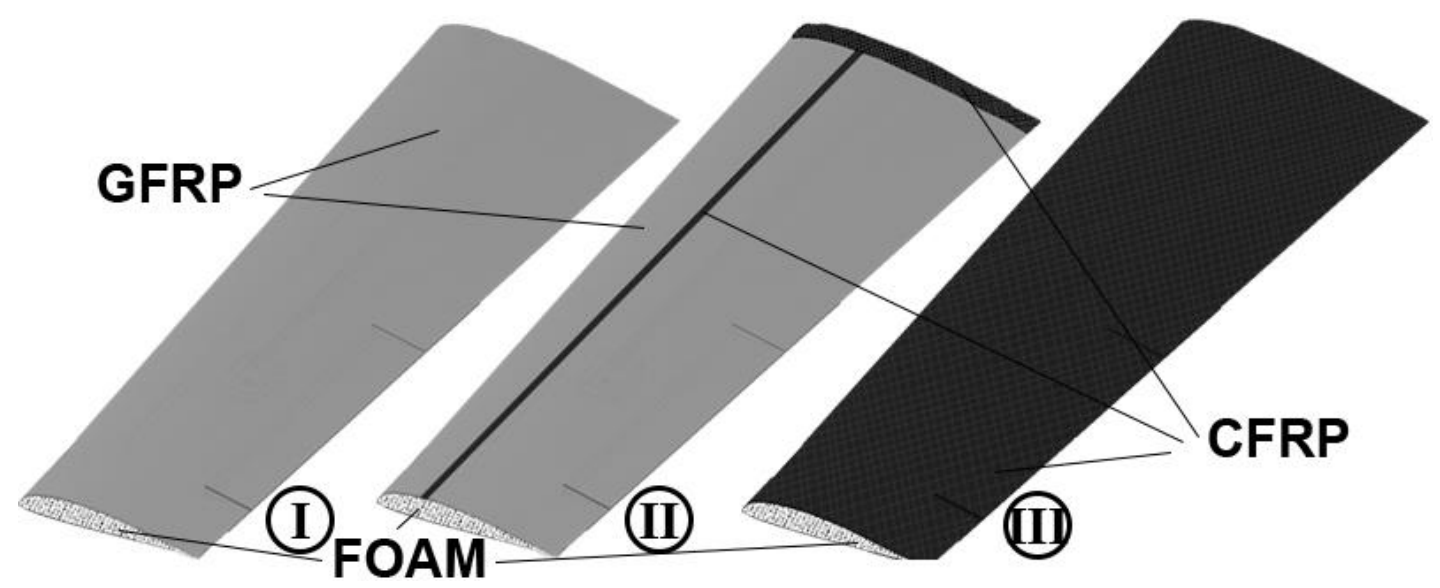

Figure 2. Wing materials and stepped manufacturing procedure: (I) foam core with two layers of woven GFRP, (II) CFRP unidirectional over the span and woven in the root for stiffening; and (III) inclusion of two final layers in CFRP fabric. 
Sensors are installed between the layers of GFRP and the CFRP. Bicomponent adhesive HBM X60 is used over the full length of the fiber to fixed it to the wing. A view of the extrados during the manufacturing process after placing the sensors can be seen in Figure 3.

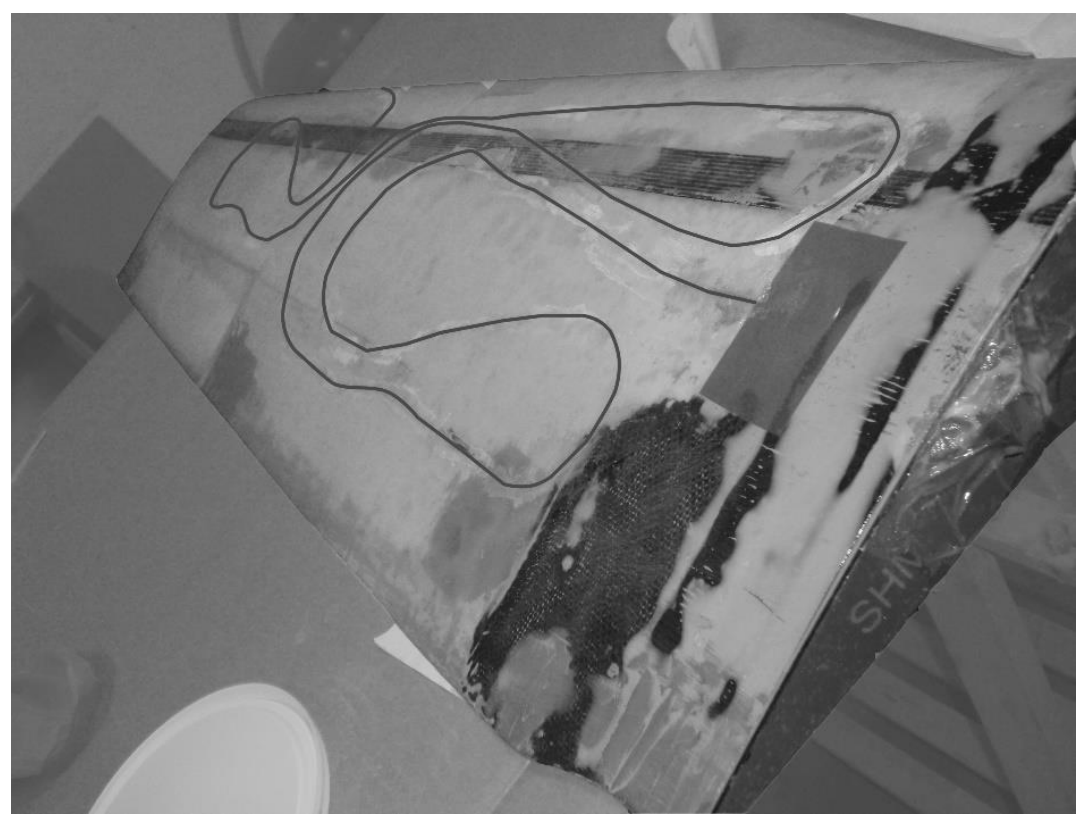

Figure 3. Wing view during the manufacturing process after the GFRP layer and fiber sensors installation (fiber has been artificially enhanced for visualization purposes).

\subsection{FEM modelling}

Following, Patran-Nastran is used as FEM software for estimating static and dynamic characteristics of the wing. GFRP, CFRP and foam materials properties introduced in the model are shown in Table 1. The wing is manufactured using hand wet lay-up by a group of non-expert people. For so, selecting the adequate material properties is a tough task. The indicated properties have been selected considering different web and manufacturers references (Matweb, 2015)(AKSACA, 2013) and the uncertainties of the process.

Figure 4 shows the mesh in extrados and intrados. The mesh for biparametric surfaces was chosen as 'Isomesh' with 'cquad' elements. For non biparametric ones, 'paver' mesh and 'tria' elements were selected. 'cquad' elements were used mainly in root, tip, leading 
and trailing edge. The center was modelled by 'tria' elements. The numerical model is clamped along the root, where the elements are finest to study the strain gradients due to this boundary condition. The static problem (Nastran solution 101) is solved considering several load cases where a point force at the tip, perpendicular to the middle plane of the structure was applied. Moreover, a modal analysis (Nastran solution 103) is done to obtain the mode shape and the natural frequencies of the model. The computed results will be discussed in Section 4.

Table 1. Materials and properties introduced in FEM model.

\begin{tabular}{|c|c|c|c|c|c|c|}
\hline Material & $\begin{array}{l}\mathrm{E}_{\mathrm{XX}} \\
{[\mathrm{GPa}]}\end{array}$ & $\begin{array}{l}\mathrm{E}_{\mathrm{YY}} \\
{[\mathrm{GPa}]}\end{array}$ & $\begin{array}{l}\mathrm{E}_{\mathrm{ZZ}} \\
{[\mathrm{GPa}]}\end{array}$ & $\begin{array}{l}\mathrm{N}_{\mathrm{XY}}, v_{\mathrm{XZ}}, v_{\mathrm{YZ}} \\
{[-]}\end{array}$ & $\begin{array}{l}\mathrm{G}_{X Y}, \mathrm{G}_{X Z}, \mathrm{G}_{Y Z} \\
{[\mathrm{GPa}]}\end{array}$ & $\rho\left[\mathrm{kg} / \mathrm{m}^{3}\right]$ \\
\hline $\begin{array}{l}\text { Foam } \\
\text { (Matweb, } \\
2015 \text { ) }\end{array}$ & 0.140 & 0.140 & 0.140 & 0.32 & 0.0520 & 30 \\
\hline $\begin{array}{l}\text { GFRP } \\
\text { (Step I) } \\
\text { (Matweb, } \\
2015 \text { ) }\end{array}$ & 25 & 25 & 8 & 0.2 & 4 & 1900 \\
\hline $\begin{array}{l}\text { CFRP UD } \\
\text { (Step II) } \\
\text { (Matweb, } \\
\text { 2015)(AKS } \\
\text { ACA, } \\
\text { 2013) [a] }\end{array}$ & 175 & 10 & 10 & 0.3 & 5 & 1600 \\
\hline $\begin{array}{l}\text { CFRP } \\
\text { fabric } \\
\text { (Step III) } \\
\text { (Matweb, } \\
\text { 2015)(AKS } \\
\text { ACA, } \\
2013 \text { ) }\end{array}$ & 85 & 85 & 10 & 0.1 & 5 & 1600 \\
\hline
\end{tabular}

[a] UD stands for Unidirectional 

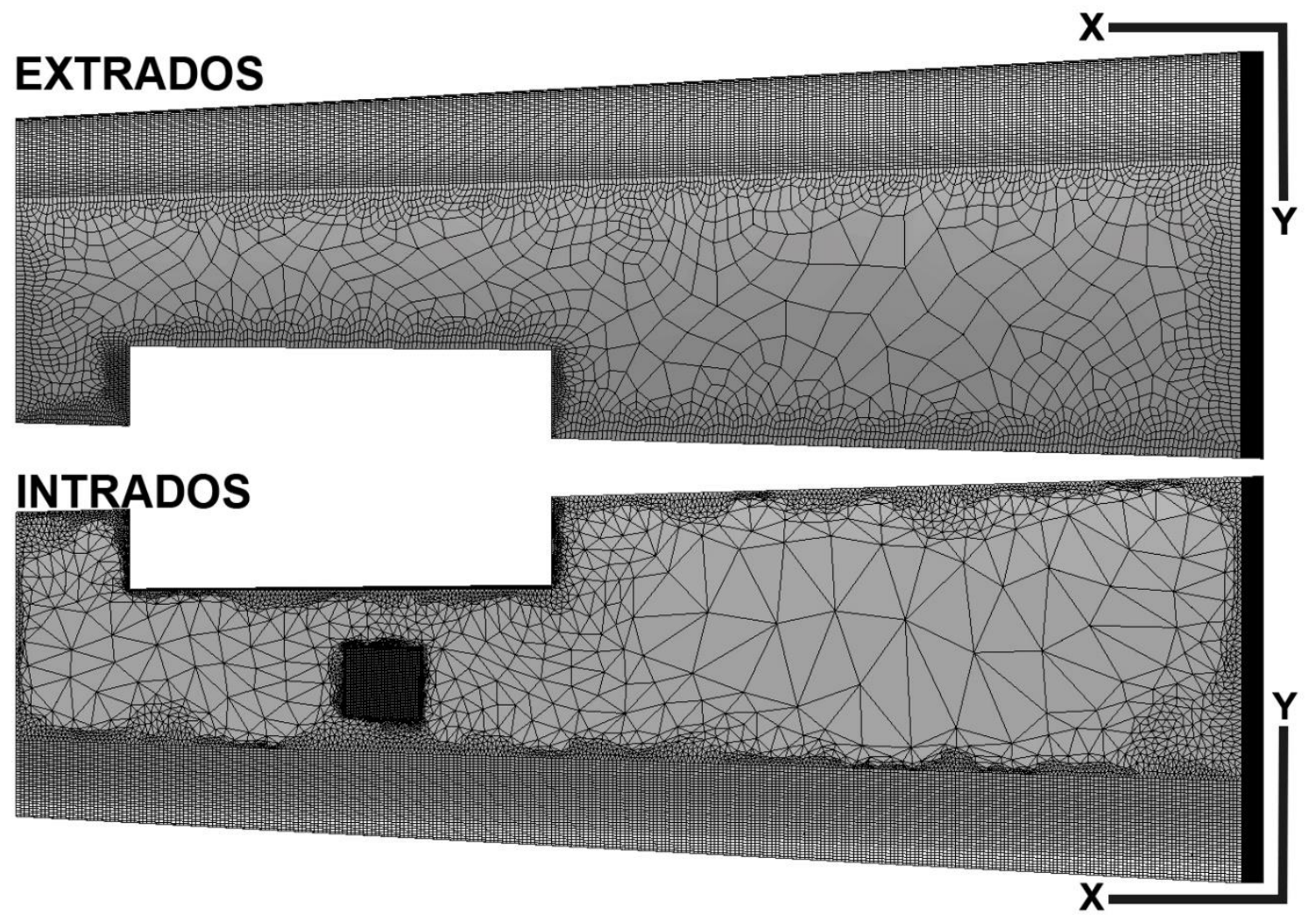

Figure 4. Mesh for FEM model of the UAS wing (extrados and intrados): 'tria' elements in the center, 'cquad' in leading and trailing edge, root and tip.

\subsection{FBG monitoring system}

Integrating FBGs in aircrafts or UAS allows many capacities (some of them still need to be further developed in near-mid-term): i) checking and controlling the curing quality, related with temperature, pressure and time of the composite fabrication process (Gutiérrez et al., 2013), the cure controlling is a hot research topic nowadays with many groups pushing into it (Hudson et al., 2018; HS Kim et al., 2013; Mortensen et al., 2018; Schubel et al., 2013); ii) any shape distortion during fabrication, such as springbacks or warpages, could be detected and characterized; iii) damage produced during handling can be identified before assembly, reducing time and costs of quality control (Shrestha et al., 2015; Zhu et al., 2017); iv) monitoring of strain level, that can be useful to UAS operators and autopilots for controlling that safety thresholds are not overpassed during aggressive maneuvers or operations; v) the shape of UAS fuselage and wings can be 
estimated from the strain field (H-I Kim et al., 2013; Xu et al., 2016); vi) automatic deployment of mechanisms, based on structural response, can be planned under expected circumstances (for example, an aileron or spoiler can be oriented to reduce loading on the structure, a parachute deployed or a moving winglet activated); vii) maintenance, repair and overhaul technicians can access to number and level of load cycles, severity and localization of impacts and viii) finally, the monitoring allows to update numerical models for improving designs, calculations and manufacturing techniques.

Some of the previously cited capabilities are tested in this work. To do so, different algorithms are developed in simple and computationally inexpensive scripts for showing the responsiveness and robustness of the monitoring system in real time. The following features are checked: i) a strain threshold level close to the wing fixed end, where the highest strain level is expected; ii) estimation of the deflection shape; iii) automatic deployment of the aileron; and iv) load cycles counting. Moreover, an algorithm to detect resonance responses is implemented but not in real time.

\subsection{FBG installation}

Optimal FBG sensors network installation is in itself an important research field that seeks to minimize the number of sensors to achieve the objectives of the monitoring system. Several researchers are working on optimal sensor location for SHM (Beal et al., 2008; Chisari et al., 2016; Kammer, 1991). In the present research, the location of the sensor is obtained from a combination of FEM analysis and manufacturing constraints.

The wing profile is round and wide in leading edge and sharp and narrow in trailing edge. From the numerical results, it was concluded that bending and torsion contribute to the wing response. However, the structural deflection is mainly dominated by the bending contribution due to the aspect ratio and properties of the wing. For increasing sensitivity to static loads, sensors should be placed as close as possible to the root and the maximum thickness of the wing. But to identify the mode shapes, they should be installed in regions of high modal strains (eigenmodes obtained from FEM can be seen in Figure 11).

For this work, 5 FBG sensors are available and they were previously manufactured with a separation of 1 meter between them. Cutting and welding the fiber was not considered in 
order to avoid fiber weaken and breakages. The length between the sensors needed to be placed in the wing avoiding sharp turns and crossings, circumventing the aileron and the servo box. The connector to the interrogation system needed to be positioned on the root of the wing. Taking all these aspects into account, the sensors were finally installed as in Figure 5 to accurately measure the strain field along the wing in both intrados and extrados. Three sensors are located at extrados and two at intrados. The sensors are placed in the area from the fixed end to $66 \%$ of the span and from leading edge to $66 \%$ of chord for measuring the highest strain. Four sensors are aligned with the span and one is turned to record the torsion contribution.

\section{EXTRADOS}

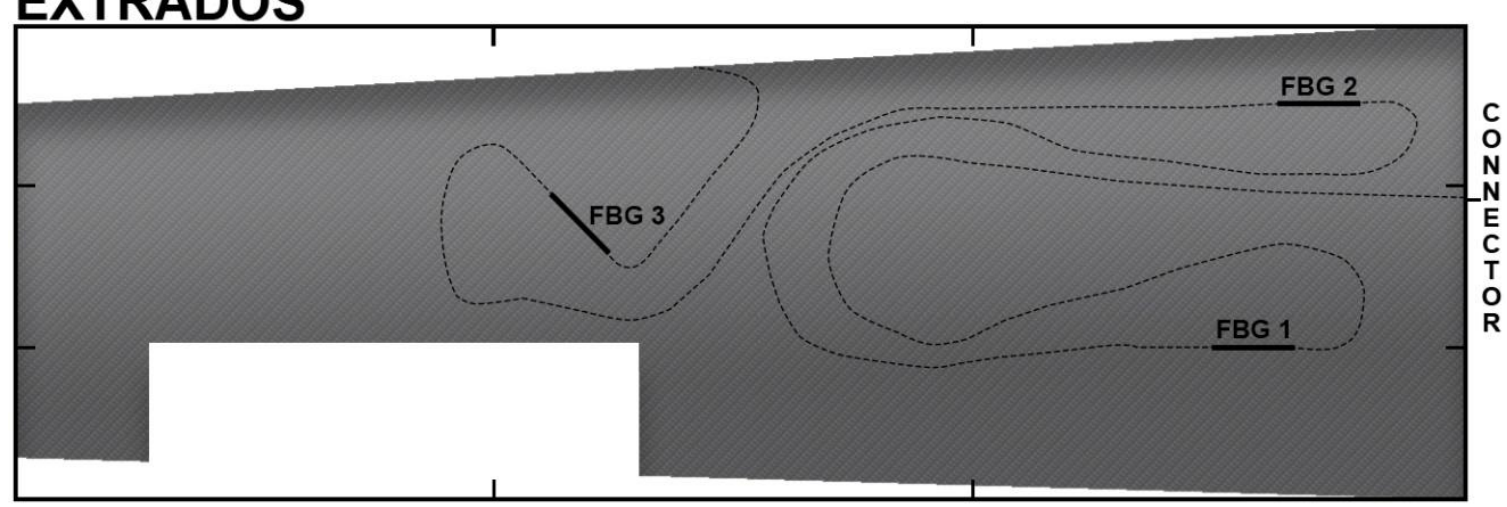

\section{INTRADOS}

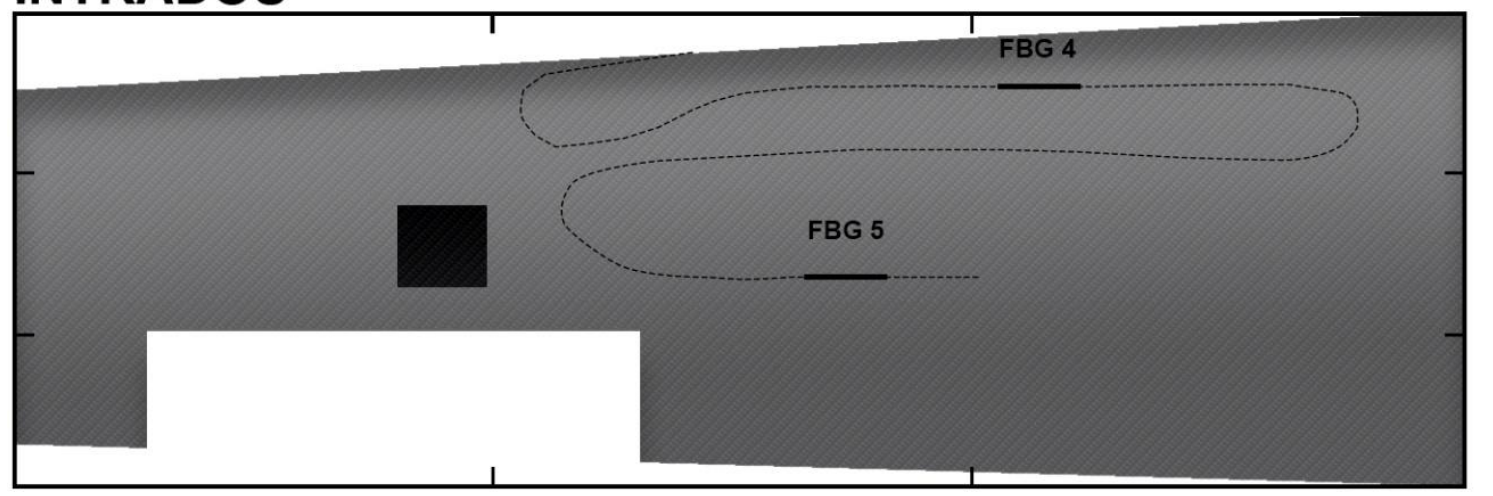

Figure 5. Sensors placement in extrados and intrados: FBGs (solid line) and fiber chord (dashed line).

The fiber spectrum after the manufacturing process with no load is depicted in Figure 6. 5 peaks can be seen corresponding to every sensor. From FBG1 to FBG5, registered wavelength of each sensor is, respectively: 1527.125, 1537.206, 1546.964, 1556.937 and $15671.394 \mathrm{~nm}$. 


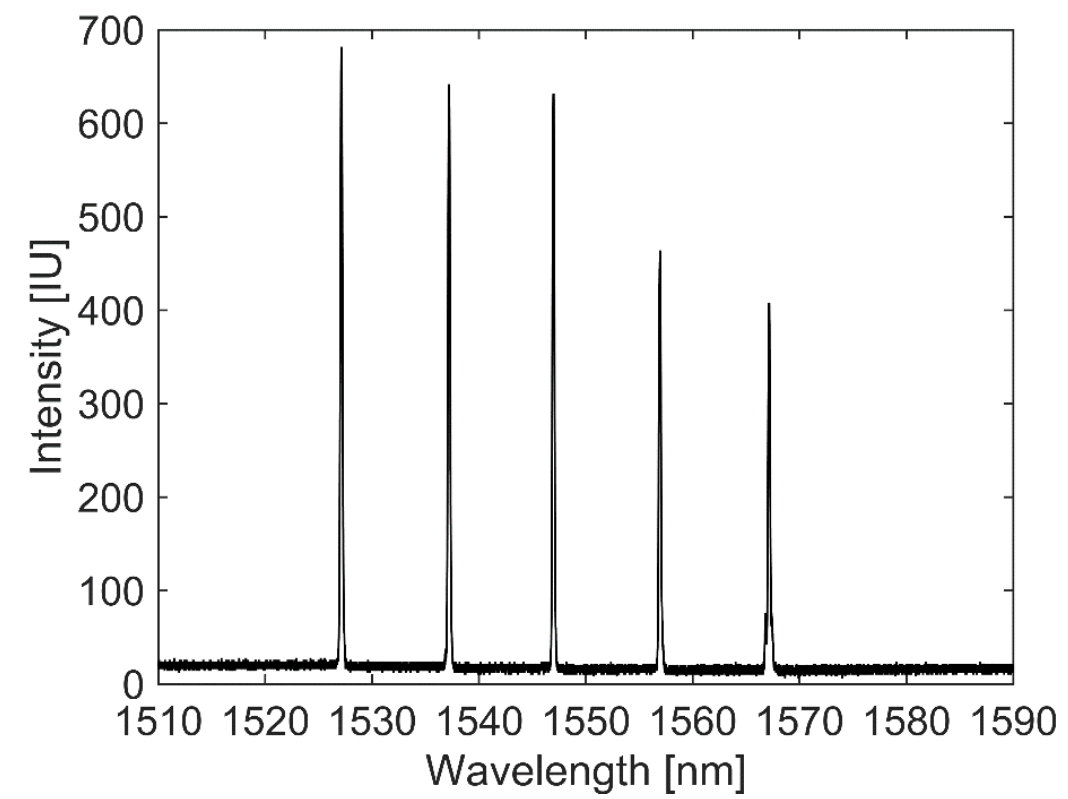

Figure 6. Spectrum read from the FBG line after manufacturing process.

\section{Testing and results}

The wing is clamped along the root by an aluminum auxiliary structure and steel screws. The structure was excited by three load cases. In the first case, a point load was applied at the leading edge (Load case 1); in the second one, at 25\% chord (Load case 2); and in the third case, at the trailing edge (Load case 3). In this section, load case 2 is analyzed. The load cases 1 and 3 were also studied and similar conclusions are obtained.

Firstly, static tests are discussed (Figure 7). Bending and bending-torsion tests were carried out by a universal testing machine model Zwick Z100. The tests were controlled at a speed of $1 \mathrm{~mm} / \mathrm{min}$. A $70 \mathrm{~N}$ vertical load was applied using a steel wire. 

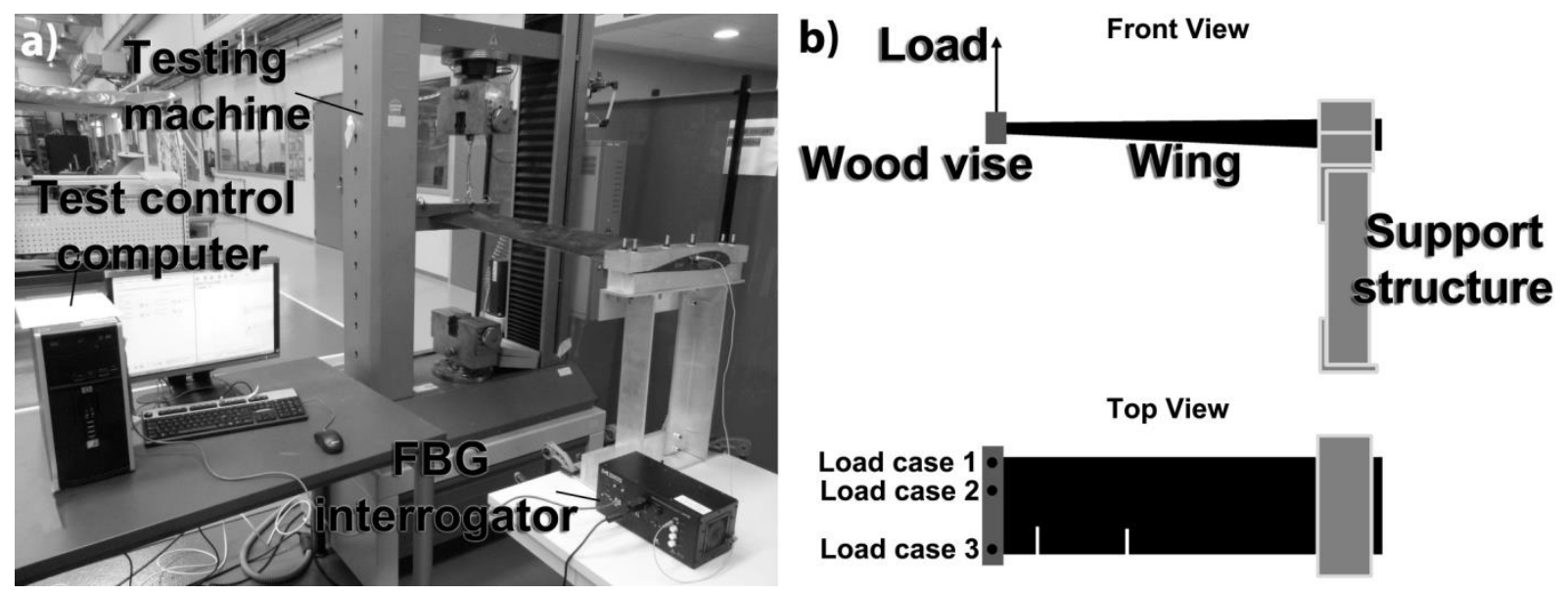

Figure 7. (a) Static tests experimental set-up and (b) drawings.

Following, the experimental results are compared with those obtained from the numerical model. Figure 8 shows the numerical and the experimental results for the load case 2 . The load was applied from intrados to extrados. Therefore, the sensors located at the extrados measures negative strain (compressive), while those situated at the intrados recorded positive values (tensile). The strains corresponding to the maximum load are -108, -264, 51, 191 and $132 \mu \varepsilon$ for sensors FBG1 to FBG5, respectively. FBG1 and FBG2 present a perfect linear response. FBG3, FBG4 and FBG5 exhibit an oscillating behavior deviating from linearity a maximum value of 7,15 and $17 \mu \varepsilon$, respectively. The highest absolute value was registered at FBG2 since it is located close to the root, at the maximum thickness zone of the profile. The minimum strain value was recorded by the FBG3, which it is the sensor farthest to the fixed end. As it is expected, the numerical results present a linear response. The maximum computed strains at the locations of FBG1 to FBG5 are $-111,-296,-51,262$ and $98 \mu \varepsilon$, respectively. Experimental and numerical results for sensors FBG1 and FBG3 present a good agreement with differences lower than $3 \%$. The comparisons of the numerical and experimental results from FBG2, FBG4 and FBG5 show differences of 12.5, 25 and 26\%, respectively. Slopes obtained through linear regression show a difference, respectively from FBG1 to FBG5, of 2.8, 11.6, 3.6, 33.1 and $31.3 \%$. FBG4 and FBG5 discrepancies are explained by manufacturing issues. Intrados was cured with some waving caused by handling and vacuum bag sealing. The mismatches for the FBG2 are caused by an error with the final location of this sensor, which it is located closer to the root than planned. 


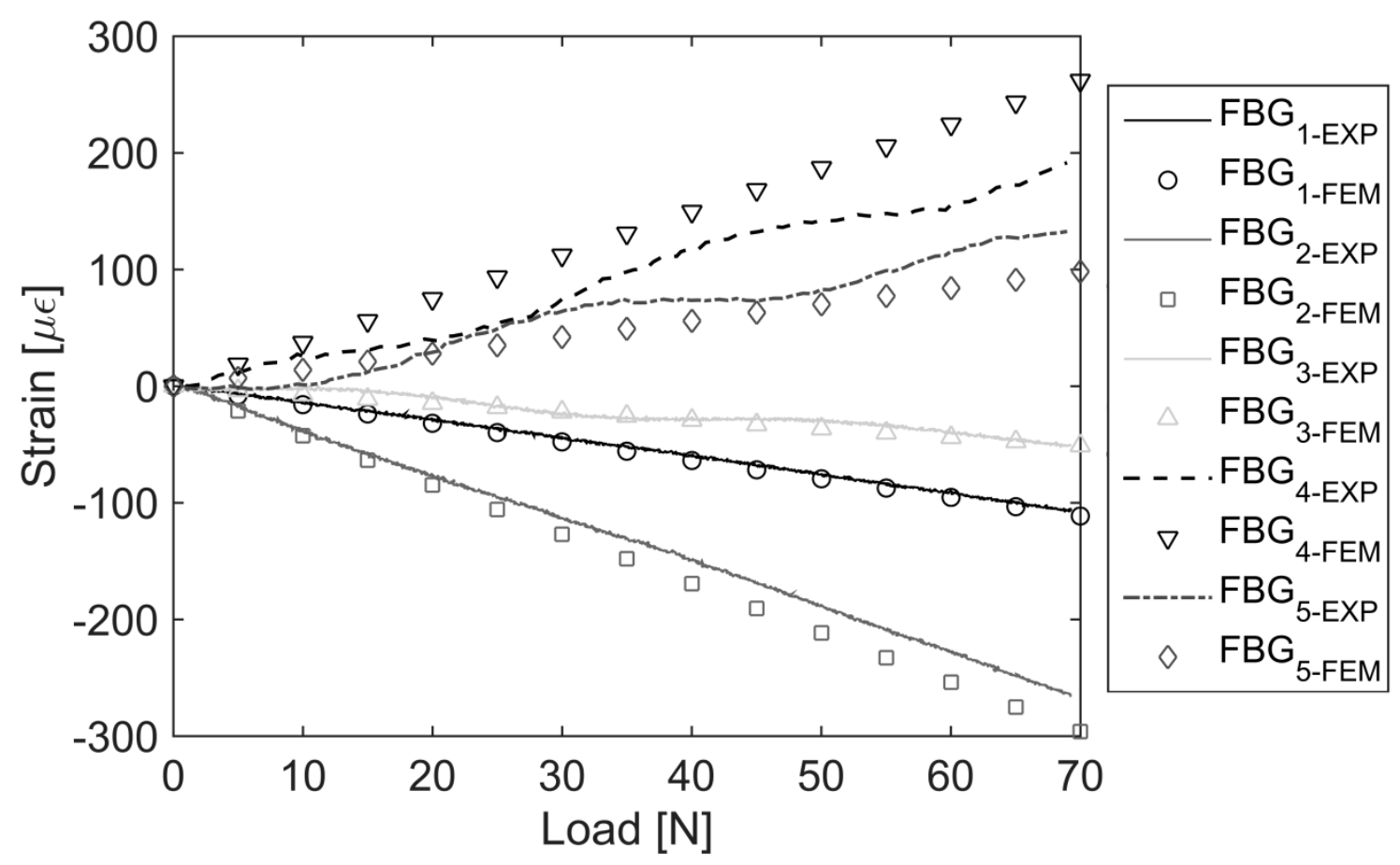

Figure 8. Strain response for the load case 2: experimental (EXP) and numerical results (FEM).

Secondly, the dynamic experimental campaign is discussed. Figure 9 shows the set-up. A modal analysis was developed using a shaker, an amplifier and a signal generator. The shaker is a model The Modal Shop 2025E with a maximum force of $58 \mathrm{~N}$ and a maximum displacement of $18 \mathrm{~mm}$. The sine sweep force was applied by a $2 \mathrm{~mm}$ diameter bar at the tip at a frequency range from 0 to $200 \mathrm{~Hz}$.
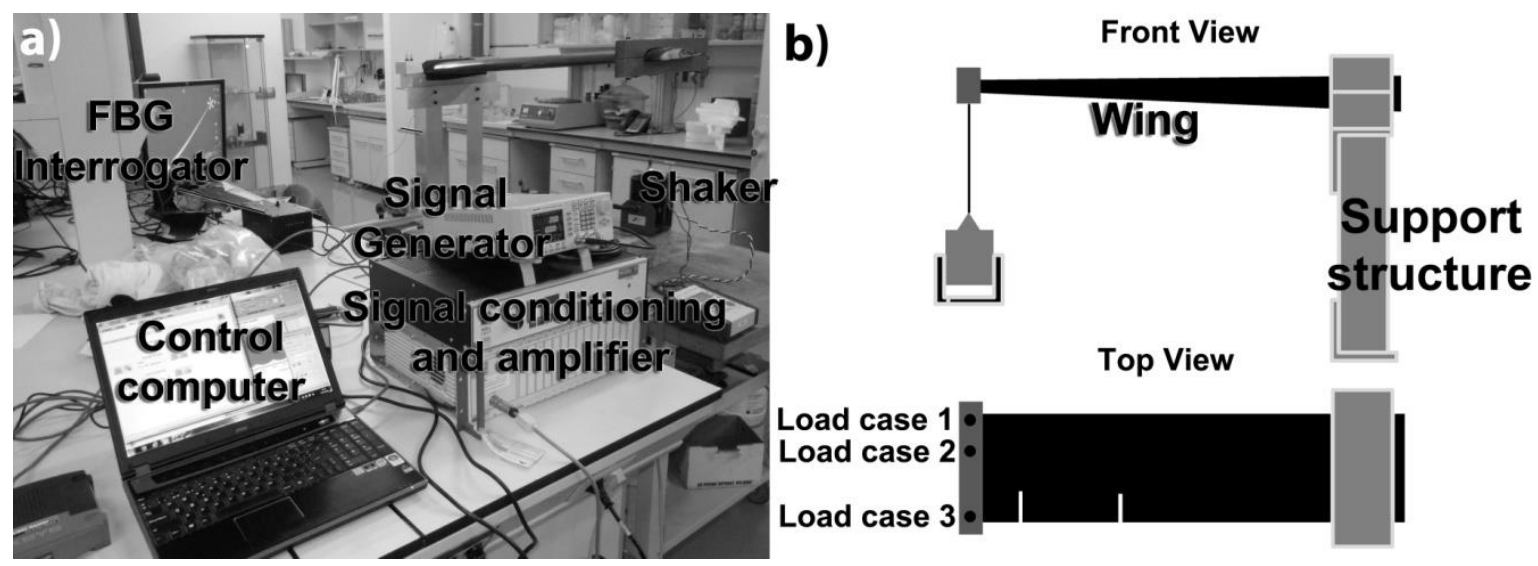

Figure 9. (a) Dynamic tests experimental set-up and (b) drawings. 
Peak picking methodology is used for modal parameter identification (natural frequencies, mode shape and modal damping) assuming that the modes are uncoupled and slightly damped. The modal damping ratios are estimated from the structural responses due to a harmonic load at the corresponding resonance frequencies using the half power bandwidth method. Figure 10 shows the frequency response of the strain for all load cases. In Figure 10(a), peaks at $47 \mathrm{~Hz}$ and $95 \mathrm{~Hz}$ corresponding to natural frequencies can be clearly observed. The estimated modal damping ratios are $0.35 \%$ and $0.52 \%$, respectively. In load case 1 (leading edge) peaks appear at $50 \mathrm{~Hz}$ and $100 \mathrm{~Hz}$ and $47 \mathrm{~Hz}$ and $98 \mathrm{~Hz}$ for the load case 3 (trailing edge). Figure 12 shows the normalized modal strain corresponding to both natural frequencies.

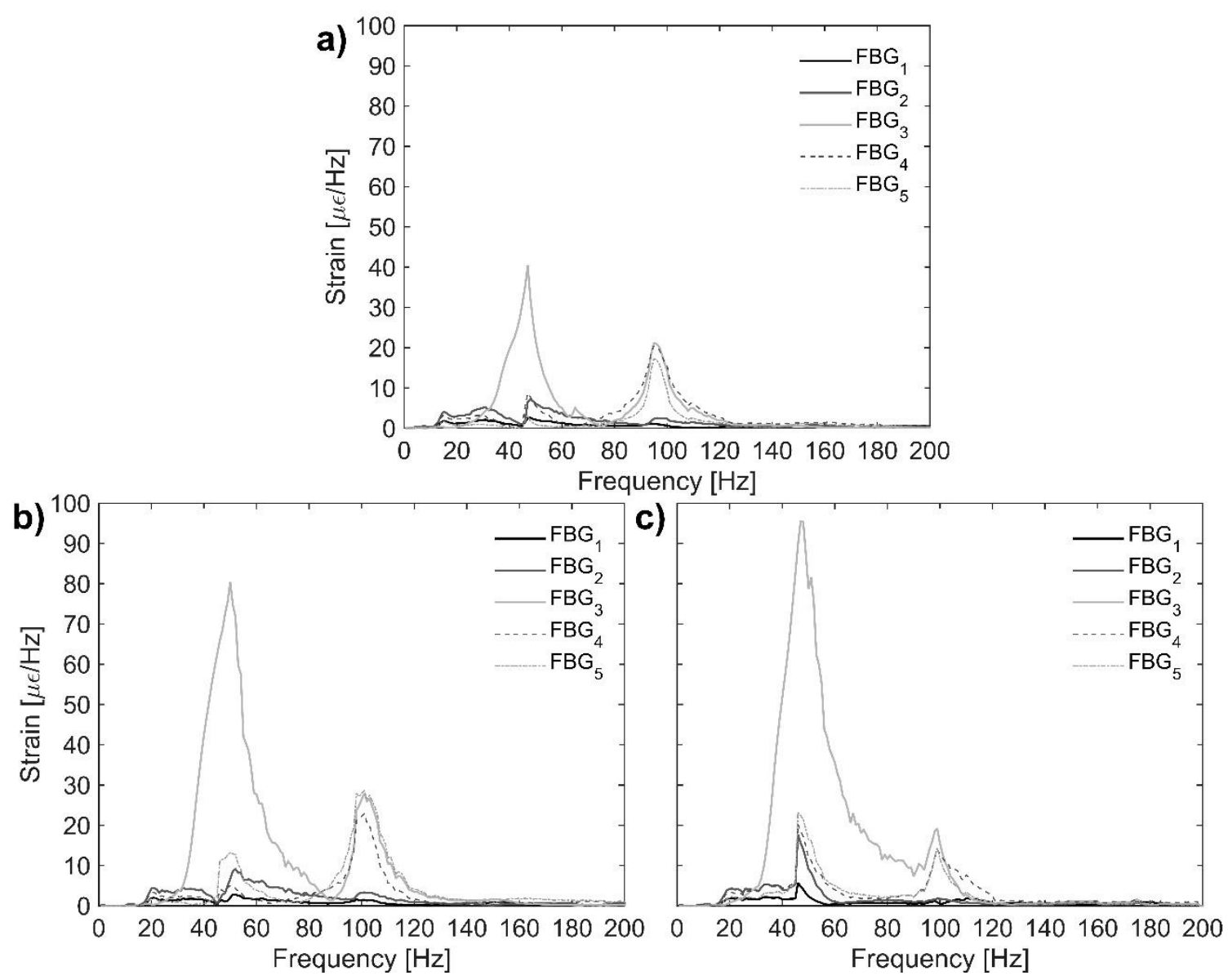

Figure 10. Frequency content of the strain for the load case: a) 25\% chord (load case 2), b) leading edge (load case 1) and c) trailing edge (load case 3 ). 
Figure 11 and Figure 12 show the modeshapes/natural frequencies and the modal strains computed by the FEM, respectively. In that case, three natural frequencies are obtained in the frequency range from 0 to $200 \mathrm{~Hz}$. However, the natural frequency at $67 \mathrm{~Hz}$ is not identified from the experimental results. Figure 12 shows the modal strains normalized based on maximum component for each mode shape.

Next, the experimental records are compared with the results computed from the numerical model. The agreement between numerical and experimental results for the first mode shape is quite good. Some minor mismatches appear from the sensors located at the leading edge (FBG2 and FBG4). The mode shape at $95 \mathrm{~Hz}$ presents a nice agreement for sensors FBG1 and FBG3, both centered respect to the chord at the extrados. However, some differences are appreciated for FBG2, FBG4 and FBG5.

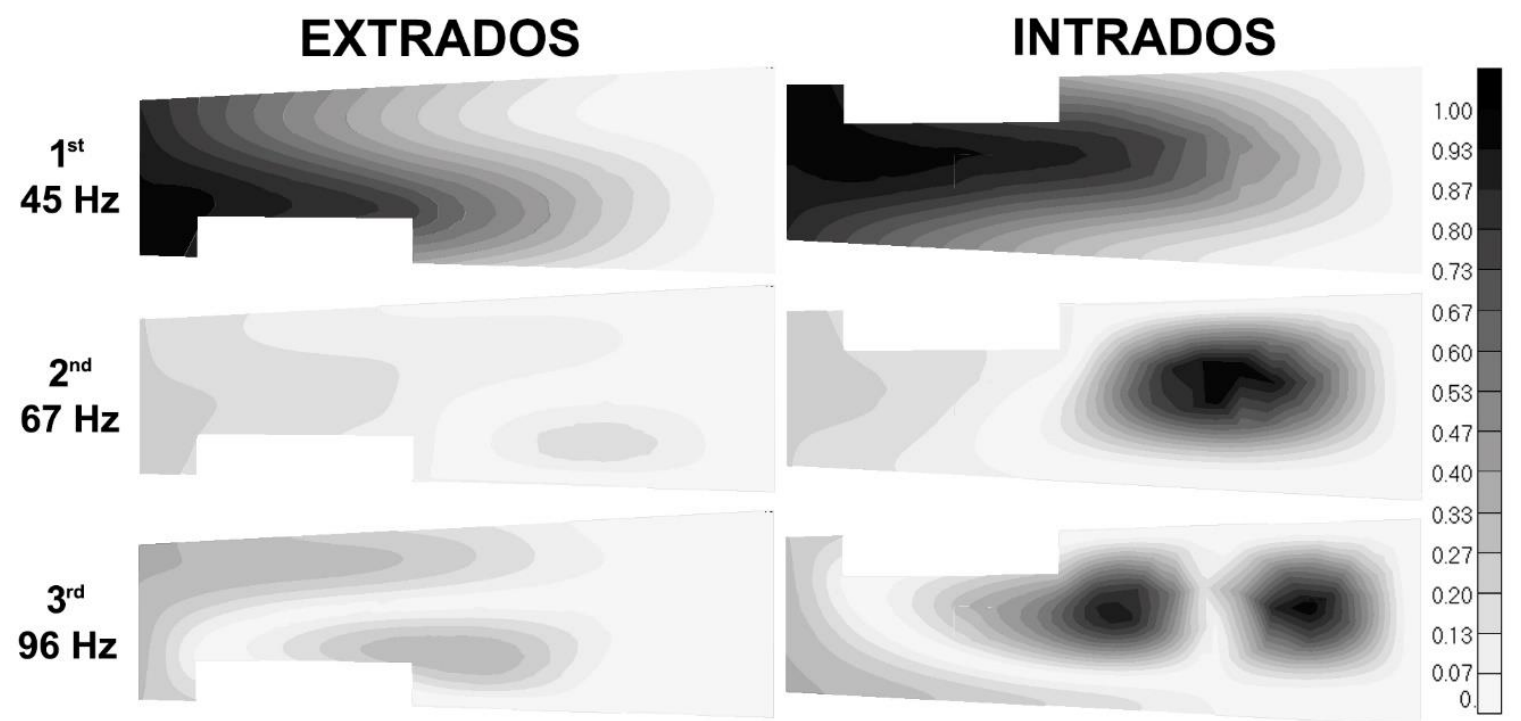

Figure 11. Modeshapes and natural frequencies obtained from FEM model.

In order to do a numerical quantification of the previous comparison, the Modal Assurance Criterion (MAC) given by Equation 3 is considered (Allemang and Brown, 1983):

$$
\operatorname{MAC}\left(\varphi_{i}^{E X P}, \varphi_{i}^{F E M}\right)=\frac{\left(\varphi_{i}^{E X P^{T}} \varphi_{i}^{F E M}\right)^{2}}{\left(\varphi_{i}^{E X P^{T}} \varphi_{i}^{E X P}\right)\left(\varphi_{i}^{F E M^{T}} \varphi_{i}^{F E M}\right)}
$$


where $\varphi_{i}$ means the mode shape $i$, with $i$ equals to 1 and 3 , and $T$ means transpose vector. MAC values vary from 0 to 1 ; a value of one implies perfect correlation of the two modes vectors (one vector is proportional to the other), while a value close to zero indicates no correlated modes (orthogonal modes). The MAC values corresponding to mode shapes at $47 \mathrm{~Hz}$ and $95 \mathrm{~Hz}$ are 0.97 and 0.81 , respectively. Therefore, a reasonable good agreement is obtained accounting for the uncertainties of the structure manufacturing.
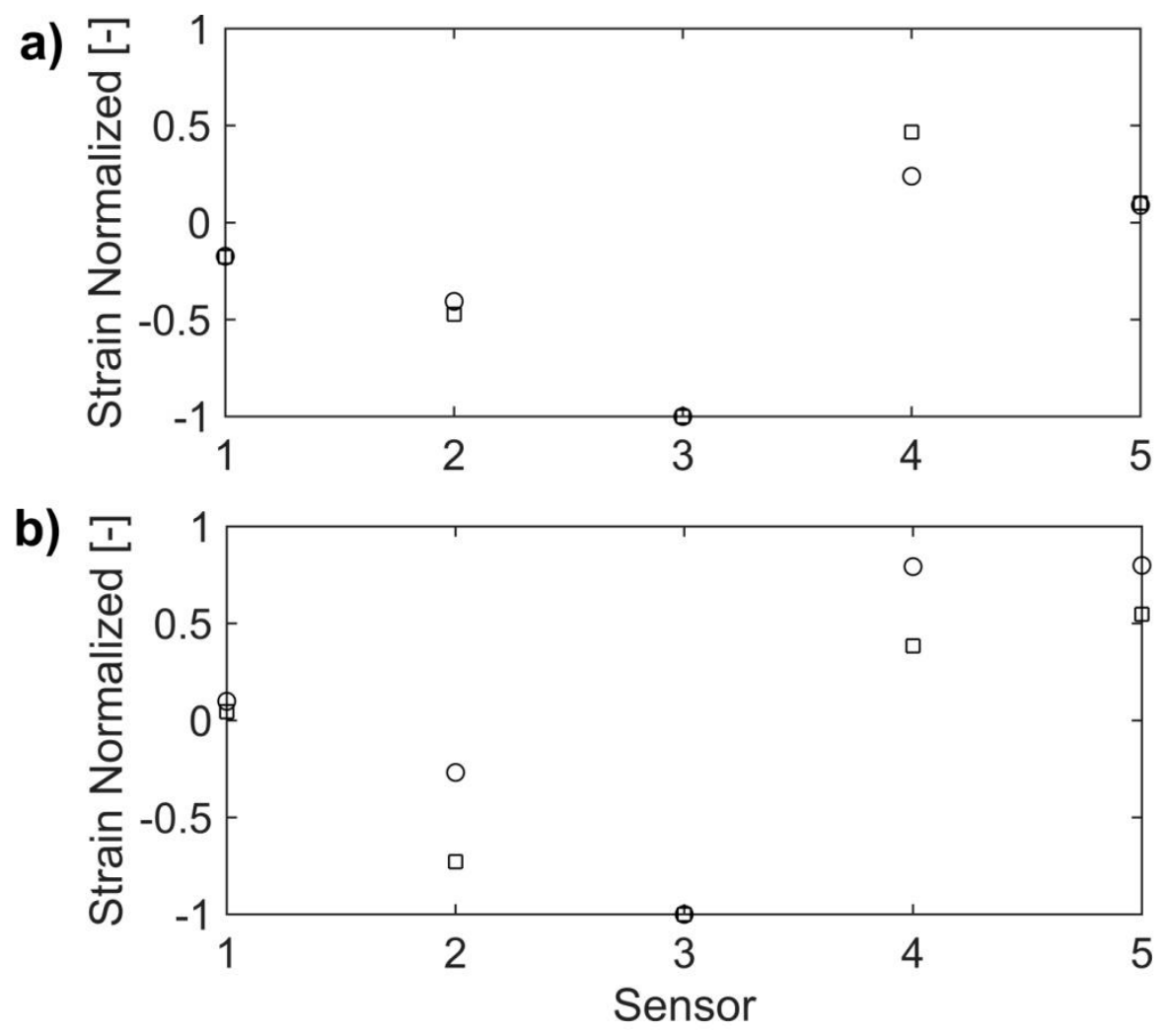

Figure 12. a) First and b) third modal strain: experimental (circles) and numerical (squares) results.

Finally, some operational capabilities of the monitoring system are studied (See the video in the online version). The interface of the software developed for these features is shown in Figure 13. The strain cycle counting algorithm is validated using the set-up shown in Figure 9. The number of cycles is accurately estimated in real time without any delay. The amplitude of each load cycle is also good estimated. A damage index based on fatigue cycles is included only for visualization purposes. A realistic damage accumulator 
would need a deeper study including some specimens being tested up to failure, and for so it is out of the scope of this work. The deflection shape is obtained by a linear combination of bending and torsion responses measure by the FBG sensors. Audible alarm sounds when the absolute strain from the FBG2 sensor is higher than $70 \mu \varepsilon$. This threshold was found to be an adequate quantity that allows seeing the deflection of the wing and it is fast and easy to reach pushing with hand force. In the future it could be set at any quantity depending on the mission requisites. A RGB color alarm according to the strain level is also available. Moreover, the aileron deflection is set with a linear law that it is opposed to the strain level at FBG2: the aileron is moved downwards when tension is detected, and vice versa.

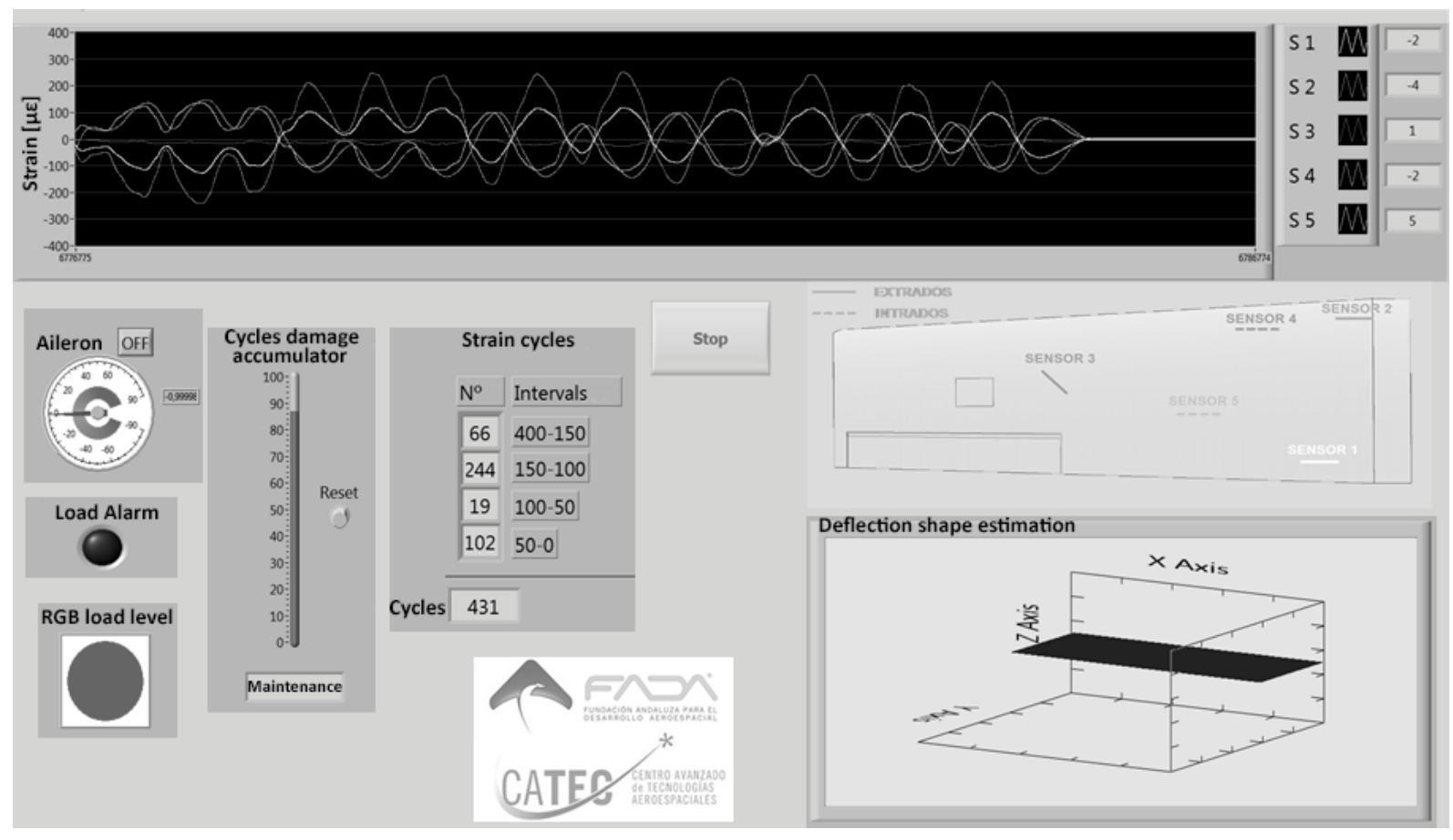

Figure 13. Software interface with real time indicators: strains from the 5 FBGs, aileron angle, load alarm, RGB load level, damage index, strain cycles quantification and deflection shape estimation.

\section{Conclusions}

In this work, five embedded FBG sensors have been used for monitoring a GFRP/CFRP UAS wing in real time. The sensors location has been based on the analysis of results 
obtained from a FEM model and manufacturing limitations. Three sensors have been positioned at extrados and two at intrados; four of them have been aligned in the span direction and the fifth has been turned $45^{\circ}$ to measure torsion response.

The monitoring system has shown several capabilities. The wing strain field has been recorded. Audible and visual alarms have been implemented at considered strain levels. The wing deflection and the cycles counting have been well identified. Moreover, resonance responses have been detected by a study in the frequency domain. The agreement between numerical and experimental results is quite good, especially considering the manufacturing process by hand.

The presented study has shown that the introduction of FBG sensors in a structure allows assessing its structural response in real time.

\section{Acknowledgments}

The authors are grateful to Juan Gutiérrez and Carmen Curiel for their support regarding manufacturing and FEM modelling. Big thanks go also for the Avionics and Systems division at CATEC for helping in the development of this work, especially to Antidio Viguria, Manuel García Rivero, José Ramón López Ladrón de Guevara and Adam Bell.

\section{Funding}

Prof. Galvín would like to acknowledge the financial support provided by the Spanish Ministry of Economy and Competitiveness (Ministerio de Economía y Competitividad) under the research projects [BIA2013-43085-P and BIA2016-75042-C2-1-R]. 


\section{References}

AKSACA (2013) AKSACA 3K A-38 Technical Data Sheet. 2652(August 2007): 1-5.

Available at: www.aksaca.com.tr.

Aktaş E, Seaver M, Nichols JM, et al. (2009) The Influence of Low Energy Impacts on the Static and Dynamic Response of a Foam Core Composite Wing. Journal of Intelligent Material Systems and Structures 20(11): 1351-1361. DOI: 10.1177/1045389X08095184.

Allemang R and Brown D (1983) Correlation coefficient for modal vector analysis. In: Proceedings of international modal analysis I, 1983, pp. 110-6.

Analog Devices (2008) TMP36 DataSheet. Available at: http://ctms.engin.umich.edu/CTMS/Content/Activities/TMP35_36_37.pdf.

Arsenault TJ, Achuthan A, Marzocca P, et al. (2013) Development of a FBG based distributed strain sensor system for wind turbine structural health monitoring. Smart Materials and Structures 22(7): 75027. DOI: 10.1088/0964-1726/22/7/075027.

Balageas DL (2002) Structural health monitoring R \& D at the 'European Research Establishments in Aeronautics' (EREA). Aerospace Science and Technology 6(3): 159-170. DOI: 10.1016/S1270-9638(01)01140-3.

Beal JM, Shukla A, Brezhneva OA, et al. (2008) Optimal sensor placement for enhancing sensitivity to change in stiffness for structural health monitoring. Optimization and Engineering 9(2): 119. DOI: 13894420 (ISSN).

Chisari C, Macorini L, Amadio C, et al. (2016) Optimal sensor placement for structural parameter identification. Structural and Multidisciplinary Optimization. Structural and Multidisciplinary Optimization. DOI: 10.1007/s00158-016-1531-1.

Choi M, Kim Jinseong, Kim Y, et al. (2010) Development of Sensor Integrated Composite Wing Structure. Advanced Materials Research 123-125: 903-906. DOI: 10.4028/www.scientific.net/AMR.123-125.903.

Doebling SW, Farrar CR, Prime MB, et al. (1996) Damage identification and health monitoring of structural and mechanical systems from changes in their vibration characteristics: a literature review, Technical Report. DOI: 10.2172/249299. 
Farrar CR and Worden K (2007) An introduction to structural health monitoring. Philosophical transactions of the Royal Society 365(1851): 303-15. DOI: 10.1098/rsta.2006.1928.

Fernández R, Gutiérrez N, Jiménez H, et al. (2016) On the Structural Testing Monitoring of CFRP Cockpit and Concrete / CFRP Pillar by FBG Sensors. Advanced Engineering Materials: 12-18. DOI: 10.1002/adem.201600065.

Frövel M (2006) Sensores de fibra óptica tipo redes de Bragg embebidos en material compuesto para medir deformaciones y temperaturas criogénicas. $\mathrm{PhD}$ thesis. Escuela Técnica Superior de Ingenieros Aeronauticos, Universidad Politécnica de Madrid. Available at: http://oa.upm.es/459/1/MALTE_FROVEL.pdf (in Spanish).

García I, Zubia J, Durana G, et al. (2015) Optical Fiber Sensors for Aircraft Structural Health Monitoring. Sensors (Basel, Switzerland) 15(7): 15494-519. DOI: $10.3390 / \mathrm{s} 150715494$.

Gutierrez N (2018) Monitorización estructural SHM mediante redes de Bragg, PhD Thesis. University of Seville. Available at: http://personal.us.es/pedrogalvin/phdguti-18a.pdf.

Gutiérrez N, Fernández R, González S, et al. (2013) Monitoring of Curing in CFRP by means of Embedded Fiber Optics Sensors. In: International Conference on Composite Structures (ICCS17), Porto (Portugal), 2013. Available at: http://paginas.fe.up.pt/ iccs17/proceeding.html.

Hudson TB, Auwaijan N and Yuan F-G (2018) Guided wave-based system for real-time cure monitoring of composites using piezoelectric discs and phase-shifted fiber Bragg gratings. Journal of Composite Materials 0(0): 21998318793512. DOI: 10.1177/0021998318793512.

International RPAS Community (2015) RPAS The Global Perspective 2015/2016 13th Annual Edition. Available at: www.uvs-info.com; www.rpas-regulations.com.

Johnson TJ, Brown RL, Adams DE, et al. (2004) Distributed structural health monitoring with a smart sensor array. Mechanical Systems and Signal Processing 18(3): 555572. DOI: 10.1016/S0888-3270(03)00002-5.

Kammer DC (1991) Sensor Placement for On-Orbit Modal Identification and Correlation of Large Space Structures. Journal of Guidance, Control, and Dynamics 
14(2)(August): 251-259. DOI: 10.2514/3.20635.

Kang D and Chung W (2009) Integrated monitoring scheme for a maglev guideway using multiplexed FBG sensor arrays. NDT \& E International 42(4): 260-266. DOI: https://doi.org/10.1016/j.ndteint.2008.11.001.

Kang DH, Park SO, Hong CS, et al. (2005) The signal characteristics of reflected spectra of fiber Bragg grating sensors with strain gradients and grating lengths. NDT and $E$ International 38(8): 712-718. DOI: 10.1016/j.ndteint.2005.04.006.

Kim H-I, Han J-H and Bang H-J (2013) Real-time deformed shape estimation of a wind turbine blade using distributed fiber Bragg grating sensors. Wind Energy 17(9): 1455-1467. DOI: 10.1002/we.1644.

Kim HS, Yoo SH and Chang SH (2013) In situ monitoring of the strain evolution and curing reaction of composite laminates to reduce the thermal residual stress using FBG sensor and dielectrometry. Composites Part B: Engineering 44(1). Elsevier Ltd: 446-452. DOI: 10.1016/j.compositesb.2012.04.021.

Kreuzer M (2006) Strain measurement with fiber bragg grating sensors. $H B M$, Darmstadt, S2338-1.0 e. Available at: https://micronoptics.com/uploads/library/documents/FBGS_StrainMeasurement_mo .pdf.

Li D, Ho S-CM, Song G, et al. (2015) A review of damage detection methods for wind turbine blades. Smart Materials and Structures 24(3): 33001. DOI: 10.1088/09641726/24/3/033001.

Li P, Liu Y and Leng J (2013) A new deformation monitoring method for a flexible variable camber wing based on fiber Bragg grating sensors. Journal of Intelligent Material Systems and Structures 25(13): 1644-1653. DOI: 10.1177/1045389X13510220.

Luyckx G, Voet E, Lammens N, et al. (2013) Residual strain-induced birefringent FBGs for multi-axial strain monitoring of CFRP composite laminates. $N D T \& E$ International 54: 142-150. DOI: 10.1016/j.ndteint.2012.11.008.

Matweb (2015). Available at: http://www.matweb.com.

Micron Optics (2008) Fiber Bragg Grating|os1100 Datasheet. Communication Research. Micron Optics (2015) Micron Optics SM130-700 website. Available at: 
http://www.micronoptics.com/product/dynamic-optical-sensing-interrogatorsm130/.

MicronOptics (2015) Fiber Bragg Grating Array polyimide coating os1200 Datasheet.: 1-2. Available at: http://www.micronoptics.com/wpcontent/uploads/2015/12/os1200_1512.pdf.

Mortensen UA, Løgstrup Andersen T, Christensen J, et al. (2018) Experimental investigation of process induced strain during cure of epoxy using optical fibre bragg grating and dielectric analysis. In: ECCM18 - 18th European Conference on Composite Materials, Athens, 2018.

O’Connor S, Kim J, Lynch JP, et al. (2010) Fatigue Life Monitoring of Metallic Structures By Decentralized Rainflow (Smasis2010-3839).: 1-9.

Park CY, Cho C-M and Jun S-M (2010) Structural Damage Monitoring of a Composite Wing Using Multiple Types of Sensors. Advanced Materials Research 123-125: 907-910. DOI: 10.4028/www.scientific.net/AMR.123-125.907.

Rao B, Gopi AG and Maione R (2016) The societal impact of commercial drones. Technology in Society 45. Elsevier Ltd: 83-90. DOI: 10.1016/j.techsoc.2016.02.009.

Rivero MG (2010) Degree Final Project: Diseño de un uav ligero de propulsión eléctrica para monitorización medioambiental. University of Sevilla, Escuela Técnica Superior de Ingeniería. Available at: http://bibing.us.es/proyectos/abreproy/60078/.

Schubel PJ, Crossley RJ, Boateng EKG, et al. (2013) Review of structural health and cure monitoring techniques for large wind turbine blades. Renewable Energy 51. Pergamon: 113-123. DOI: 10.1016/J.RENENE.2012.08.072.

Senyurek VY (2015) Detection of cuts and impact damage at the aircraft wing slat by using Lamb wave method. Measurement: Journal of the International Measurement Confederation 67. Elsevier Ltd: 10-23. DOI: 10.1016/j.measurement.2015.02.007.

Shrestha P, Kim J-H, Park Y, et al. (2015) Impact localization on composite wing using 1D array FBG sensor and RMS/correlation based reference database algorithm. Composite Structures 125. Elsevier: 159-169. DOI: 10.1016/J.COMPSTRUCT.2015.01.029.

Sohn H, Farrar CR, Hemez FM, et al. (2004) A Review of Structural Health Monitoring 
Literature : 1996 - 2001, technical report. Report number LA-13976-MS.

Solís M, Algaba M and Galvín P (2013) Continuous wavelet analysis of mode shapes differences for damage detection. Mechanical Systems and Signal Processing 40(2). Elsevier: 645-666. DOI: 10.1016/j.ymssp.2013.06.006.

Solís M, Ma Q and Galvín P (2018) Damage detection in beams from modal and wavelet analysis using a stationary roving mass and noise estimation. Strain 54(2): e12266. DOI: $10.1111 /$ str.12266.

Xu R, Yurkewich A and Patel R V (2016) Curvature, Torsion, and Force Sensing in Continuum Robots Using Helically Wrapped FBG Sensors. IEEE Robotics and Automation Letters 1(2): 1052-1059. DOI: 10.1109/LRA.2016.2530867.

Yuan S, Liang D, Shi L, et al. (2008) Recent progress on distributed structural health monitoring research at NUAA. Journal of Intelligent Material Systems and Structures 19(3): 373-386. DOI: 10.1177/1046389X07087302.

Zhao X, Gao H, Zhang G, et al. (2007) Active health monitoring of an aircraft wing with an embedded piezoelectric sensor/actuator network: II. Wireless approaches. Smart Materials and Structures 16(4): 1218-1225. DOI: 10.1088/0964-1726/16/4/033.

Zhu Q, Xu C and Yang G (2017) Experimental research on damage detecting in composite materials with FBG sensors under low frequency cycling. International Journal of Fatigue 101. Elsevier: 61-66. DOI: 10.1016/J.IJFATIGUE.2017.03.034. 